IZA DP No. 8164

Low-Skill Offshoring:

Labor Market Policies and Welfare Effects

Pablo Agnese

Jana Hromcová

May 2014 


\title{
Low-Skill Offshoring: Labor Market Policies and Welfare Effects
}

\author{
Pablo Agnese \\ FH Düsseldorf \\ and IZA
}

Jana Hromcová

Universitat Autònoma de Barcelona

Discussion Paper No. 8164

May 2014

IZA

P.O. Box 7240

53072 Bonn

Germany

Phone: +49-228-3894-0

Fax: +49-228-3894-180

E-mail: iza@iza.org

\begin{abstract}
Any opinions expressed here are those of the author(s) and not those of IZA. Research published in this series may include views on policy, but the institute itself takes no institutional policy positions. The IZA research network is committed to the IZA Guiding Principles of Research Integrity.

The Institute for the Study of Labor (IZA) in Bonn is a local and virtual international research center and a place of communication between science, politics and business. IZA is an independent nonprofit organization supported by Deutsche Post Foundation. The center is associated with the University of Bonn and offers a stimulating research environment through its international network, workshops and conferences, data service, project support, research visits and doctoral program. IZA engages in (i) original and internationally competitive research in all fields of labor economics, (ii) development of policy concepts, and (iii) dissemination of research results and concepts to the interested public.
\end{abstract}

IZA Discussion Papers often represent preliminary work and are circulated to encourage discussion. Citation of such a paper should account for its provisional character. A revised version may be available directly from the author. 


\section{ABSTRACT \\ Low-Skill Offshoring: Labor Market Policies and Welfare Effects*}

We analyze the effect of low-skill workers offshoring on the welfare of the economy. In the context of a matching model with different possible equilibria, we discuss two policies that could potentially outweigh the negative welfare effects of offshoring, namely, an increase of the unemployment benefits and the flexibilization of the labor market. Our results suggest that, while both policy instruments can theoretically bring the economy back to previous welfare levels, careful thought should be given to the practicability of either measure. In particular, while it would require a significant increase in the unemployment benefits to compensate for the negative welfare effects of offshoring, it would only take a small reduction in the vacancy cost to achieve the same outcome. Not only will this last measure be more financially advantageous, but it will avoid the strong disincentives to work that come with the adoption of the alternative.

JEL Classification: J68, F66

Keywords: offshoring, welfare, unemployment benefits, labor market flexibility

Corresponding author:

Pablo Agnese

FH Düsseldorf

Department of Business Studies

Universitätsstraße Geb. 23.32

40225 Düsseldorf

Germany

E-mail: pablo.agnese@fh-duesseldorf.de

\footnotetext{
* Financial support from the Spanish Ministry of Education and Science through grants ECO201016353, from Generalitat de Catalunya through SGR 2009-0600, is gratefully acknowledged.
} 


\section{Introduction}

Critics of offshoring are mainly concerned with the welfare effects that these business practices can have on the population at large, but especially on low-skill low-wage workers. Active measures are usually called forth to palliate these negative effects of globalization, but sometimes the remedy might turn out to be worse than the disease. This paper analyzes the welfare implications of the offshoring of low-skill activities, while discussing different usual counter measures with diverging results. We propose and evaluate two particular policies that could potentially outweigh the effects of offshoring, namely, an increase in the unemployment benefits and a reduction of the vacancy costs (broadly understood here as the flexibilization of the labor market).

Notice that, in focusing on the effects of offshoring and its immediate political reaction, we are emphasizing the interactions between trade and labor market policies for a hypothetical equilibrium. As will become clear later, our framework cannot go into the well-known welfare improving effects of offshoring, as some possibilities are left out of this preliminary study - e.g. the future recycling of low-skill workers and their increase in productivity levels. ${ }^{1}$ The policies we have chosen for discussion have been proposed on both sides of the political spectrum, and as in every other economic measure, they have been tailored to deal with difficulties in a short time horizon. It is in this light that we aim at suggesting possible policy outcomes - while giving a word of warning which calls for discretion in coping with the offshoring 'threat'.

For doing so, we build on the previous literature on matching models like Albrecht and Vroman (2002), Rogerson et al. (2005), and Davidson et al. (2008). We adapt the model in Albrecht and Vroman (2002) to our case of low-skill offshoring and then use different parameter combinations that render interesting comparative statics which can be used for policy recommendation analysis. Two equilibria are discussed: the equilibrium with cross-skill matching (CSM) and the equilibrium with ex post segmentation (EPS). CSM occurs when high-skill workers and low-skill vacancies are matched; EPS takes place when these potential matches do not meet (e.g. high-skill workers only work in high-skill jobs). Changing the model's parameters yields three scenarios: (i) a change in the CSM equilibrium to another; (ii) a switch from a CSM to an EPS equilibrium; and (iii) a change from an EPS equilibrium to another. These different scenarios, in combination with the policy measures, will produce different welfare effects.

Albrecht and Vroman (2002) propose a matching model with endogenous skill requirements where employers create both high and low-skill vacancies and where the distribution of skill requirements across theses vacancies is endogenous. It is also assumed that a low-skill job can be done by either type of worker whereas high-skill jobs

\footnotetext{
${ }^{1}$ For an interesting and intense debate on the welfare implications of offshoring see the SamuelsonBhagwati exchange (Samuelson, 2004, and Bhagwati et al., 2004).
} 
can only be done by high-skill workers. Unemployment is generated by frictions and the meeting process (undirected) is taken from Diamond (1982), Mortensen (1982), and Pissarides (2000), while the wage setting approach is of the Nash bargaining type. Low-skill workers are better off the greater the fraction of low-skill vacancies, and the opposite is true for high-skill workers. Likewise, firms with low-skill requirements are better off the greater the fraction of low-skill job candidates.

The offshoring literature has seen a recent surge in welfare analysis. For example, Mitra and Ranjan (2013) suggest that a reduction in the cost of offshoring increases offshoring and the unemployment of unskilled workers, but has a positive effect on skilled workers in the form of higher wages and lower unemployment. Ranjan (2013a) argues that some employment protection policies can play an important role in protecting workers against external shocks like offshoring. He concludes that offshoring can reduce welfare even in the presence of optimal severance payments, and that some additional redistribution program might be needed to ensure welfare gains. He also points out that employment protection in the form of administrative cost of firing fails to protect workers as it unambiguously reduces welfare. On the same line, Ranjan (2013b) suggests that when unemployment arises due to both job destruction and matching frictions, a combination of severance payments and unemployment benefits is a better policy to shield workers from offshoring than either of them alone. Jung and Mercenier (2014), in turn, analytically derive the conditions under which all workers, including low-skill, might gain from the surge of offshoring. Their main policy implication is that government action should aim at reducing market rigidities, rather than thwarting adjustment, something that calls, for instance, for extensive and flexible re-training programs.

Before laying out the model in full, in the next few paragraphs we show the trends of offshoring worldwide. However, offshoring indicators are not easy to come by. Since Feenstra and Hanson (1996) original contribution little has been done in that direction, as the endeavor can prove sometimes difficult or even impossible. Indirect indicators, in turn, seem to be the second-best alternative. Trade indices as those shown in Figure 1 for 22 OECD countries display a clear upward trend of these business practices. ${ }^{2}$ Arguably, the higher the volume of intermediate trade, as represented, for example, by the intermediate imports or the imports contents of exports (segments $a$ and $b$ in Figure 1, respectively), the higher the offshoring intensity. The rationale, not devoid of criticism, goes as follows: as soon as 'relocated' business units start operating from abroad, the intensity of intrafirm trade, which mostly consists of parts, components, and other inputs previously produced in the home country, will grow substantially.

\footnotetext{
${ }^{2}$ These countries, for which data were available for a considerable number of years, are: Australia, Austria, Belgium, Canada, Czech Republic, Denmark, Finland, France, Germany, Italy, Japan, Korea, Netherlands, New Zealand, Norway, Poland, Portugal, Spain, Sweden, Switzerland, UK, and US.
} 
Firms are thus responding to import competition from low-wage countries by moving their non-skill intensive activities to foreign locations from which they can later import back. Both indicators in Figure 1 are consistent with the story of increasing offshoring strategies worldwide. On the down side, however, they are consistent too with growing integration and interdependency of economies across the globe; in other words, higher ratios do not necessarily always mean higher offshoring intensity.

\section{Figure 1: Offshoring trends, 5-year world averages}

(a) Intermediate import ratio

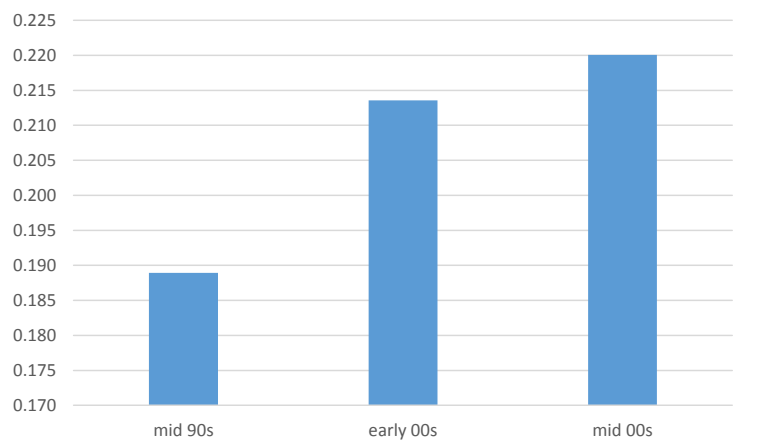

(b) Imports contents of exports

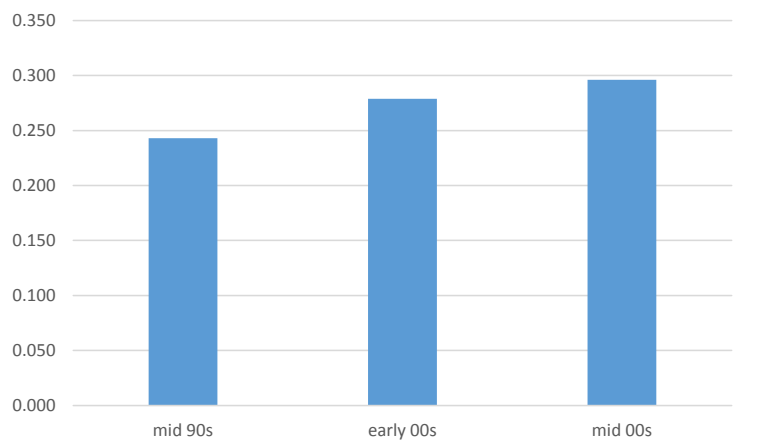

Source: OECD STAN Input-Output Database (2012).

Notes: (a) is intermediate imports in intermediate demand, and (b) is the degree of vertical specialization.

Figure 2 provides evidence on the involvement of the two major economic sectors, manufacturing and services. The indices there are broken down as to account for the level of offshoring intensity coming from both sectors. For manufacturing, the more traditional sector, offshoring strategies are still relatively much more significant, as these firms started their relocation activities much earlier; services firms, instead, are only recently beginning to show more interest. In fact, most of the offshoring taking place worldwide nowadays still includes highly repetitive low-skill occupations largely to be found in the manufacturing sector. ${ }^{3}$ Moreover, beyond what is seen in the data firm theory holds that it is lower-skill activities that become redundant earlier and are thus at risk of being relocated first. Unlike Davidson et al. (2008) we start from this hypothesis to lay out our model below and carry out our welfare analysis; that is, low-skill offshoring is significantly more prominent than high-skill and, consequently, deserving of more attention in terms of welfare effects.

The remainder of the paper is organized as follows. In section 2 the model and its main properties are stated, while possible types of equilibria are discussed. In section 3 we outline the strategy for the solution of the model. Welfare effects of proposed policies are studied in section 4 . Final remarks are summarized in section 5.

\footnotetext{
${ }^{3}$ Notice that due to the structure of the data it was not possible to distinguish between the offshoring of manufacturing and services occupations, but rather, between the offshoring emerging from both the manufacturing and services sectors, as defined by the usual measures of intermediate trade.
} 
(a) Intermediate import ratio

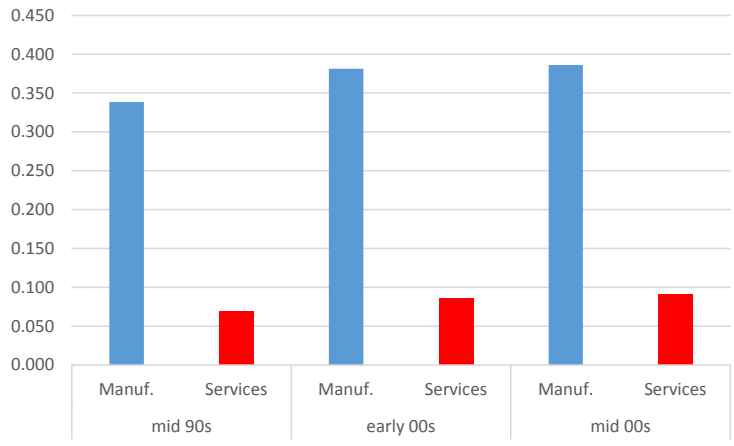

(b) Imports contents of exports

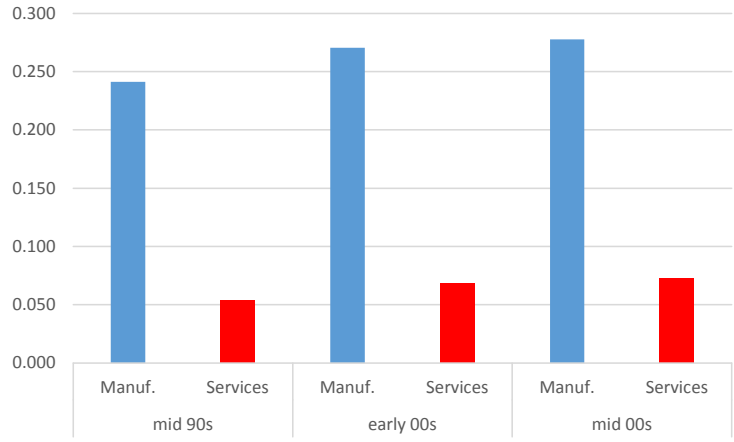

Source and notes: see Figure 1.

\section{Model}

We adapt the model in Albrecht and Vroman (2002) to the case of low-skill offshoring. ${ }^{4}$ As in there, agents are infinitely lived and there are many workers and firms of measure one. An exogenous fraction $q$ of risk neutral workers is low-skill, $L$, and the rest are high-skill, $H$. Firms place vacancies of both skill types and the cost $c$ of opening a vacancy is exogenous. A fraction $\phi$ of vacancies is low-skill and a fraction $1-\phi$ is highskill, and their the distribution is endogenous. A high-skill worker is allowed to take both types of jobs, whereas a low-skill worker can only fill a vacancy that corresponds to his type.

If a worker of any type is employed, he gets a wage corresponding to the type of vacancy and the type of skills he has. A worker of type $L(H)$ working in a job of type $L(H)$ will get a wage $w_{L}\left(w_{H}\right)$. A worker of type $H$ working in an $L$ type job will get $w_{L(H)}$. Wages earned by high-skill mismatched workers will be usually higher than wages of low-skill workers matched correctly with a low-skill job, hence $w_{H}>w_{L(H)}>w_{L} \cdot{ }^{5}$ If a worker is unemployed he is entitled to the unemployment benefit $b$, and any worker can refuse the job if his reservation wage is not met. Jobs are lost at the exogenous rate $\delta$.

In the described setup two types of equilibria may be realized: the equilibrium with cross skill matching (CSM) and the equilibrium with ex post segmentation (EPS). CSM occurs when high-skill workers and low-skill vacancies are matched, EPS takes place when these potential matches do not meet, i.e. high-skill workers only work in high-skill

\footnotetext{
${ }^{4} \mathrm{~A}$ description of how the model works for one type of worker can be found in Rogerson et al. (2005).

${ }^{5}$ In some particluar situations the market can collapse and only low-skill jobs will be offered, i.e. $\phi=1$, and consequently all wages will converge to $w_{L}$ (see Albrech and Vroman, 2002, pp. 294 and $303)$.
} 
jobs. The type of equilibria achieved depends on the expectations of high-skill workers about the labor market and their willingness to accept a low-skill job.

Firms and workers meet according to a matching technology $M(u, v)$ where $u$ represents unemployed workers (unemployment rate), and $v$ vacancies. In this process an endogenously determined fraction $\gamma$ of unemployed workers will be low-skill. Arrival of jobs to workers happens at a rate $\frac{M(u, v)}{u}$, arrival of workers to employers at a rate $\frac{M(u, v)}{v}$, and market tightness is defined as $\theta=\frac{v}{u}$. Besides, jobs arrive to workers at a rate $m\left(1, \frac{v}{u}\right)=m(\theta)$ and workers' arrival to firms takes place at a rate $\frac{\frac{M(u, v)}{u}}{\frac{v}{u}}=\frac{m(\theta)}{\theta}=z(\theta)$. If the match succeeds, the worker gets a wage $w_{i}, i=L, L(H), H$, with an expected lifetime utility $W_{i}$ from earning the wage $w_{i}$. Firms' profits depend on the level of output and the incurred costs, to wit, wages and searching. Profits are $y_{L}-w_{L}-c$ and $y_{L}-w_{L(H)}-c$ in the case that a low-skill firm employs a low and high-skill worker, respectively, and $y_{H}-w_{H}-c$ in the case that a high-skill firm employs a high-skill worker. ${ }^{6}$ High-skill firms are more productive than low-skill firms, $y_{H}>y_{L}$, while the firm's expected discounted profits are $J_{i}, i=L, L(H), H$.

If the agreement is not achieved, the worker's income corresponds to the unemployment benefit $b$ and his lifetime expected utility is $U_{j}, j=L, H$. In such a case, the firm ends up with an unfilled vacancy of value $V_{j}, j=L, H$. We thus have $W_{i}$ that stands for the value of working and $U_{j}$ for the value of unemployment, while $J_{i}$ stands for the value of the job and $V_{j}$ for the value of the vacancy for the corresponding type. There is something to bargain over if the value of working is higher than the value of unemployment $W_{H}>U_{H}, W_{L(H)}>U_{H}$ and $W_{L}>U_{L}$, and when the value of the job is higher than the value of the vacancy, $J_{H}>V_{H}, J_{L(H)}>V_{L}$ and $J_{L}>V_{L}$. Wages are set in a Nash bargaining process

$$
\begin{aligned}
w_{L} & =\beta\left(y_{L}-c\right)+(1-\beta) r U_{L}, \\
w_{L(H)} & =\beta\left(y_{L}-c\right)+(1-\beta) r U_{H}, \\
w_{H} & =\beta\left(y_{H}-c\right)+(1-\beta) r U_{H}
\end{aligned}
$$

where $\beta$ is the bargaining power of workers and $r$ is the rate at which agents discount future time periods. ${ }^{7}$

Workers may experience spells of employment and unemployment. When the flow of workers into and out of each employment state coincide, the steady-state equilibrium

\footnotetext{
${ }^{6}$ High-skill workers who occupy low-skill jobs are equally productive on that job as their low-skill counterparts, i.e. they both produce $y_{L}$.

${ }^{7}$ In the Nash bargainig process wages are chosen to maximize

$$
\max _{\left\{w_{i}\right\}}\left[W_{i}\left(w_{i}\right)-U_{j}\right]^{\beta}\left[J_{i}\left(y_{j}-w_{i}\right)-V_{j}\right]^{1-\beta} .
$$
}


is achieved. In the steady state, low-skill workers that were working

$$
E_{L}=q-\gamma u,
$$

and lose their jobs, equal the low-skill unemployed $q-E_{L}$, that find a job (right hand side)

$$
\delta E_{L}=\phi m(\theta)\left(q-E_{L}\right)
$$

and high-skill workers that were working

$$
E_{H}=1-q-(1-\gamma) u
$$

and lose their jobs, equal the high-skill unemployed $1-q-E_{H}$, that find a job (right hand side) ${ }^{8}$

$$
\delta E_{H}=m(\theta)\left(1-q-E_{H}\right) .
$$

Rewriting (5) and (7) using (4) and (6) we can get the expressions for the unemployment rate and the fraction of low-skill vacancies as in Albrecht and Vroman (2002)

$$
\begin{gathered}
u=\frac{\delta(1-q)}{m(\theta)(1-\gamma)+\delta(1-\gamma)}, \\
\phi=\frac{(1-\gamma) q m(\theta)+\delta(q-\gamma)}{m(\theta) \gamma(1-q)}
\end{gathered}
$$

\subsection{Cross Skill Matching Equilibrium}

Let us describe the equilibrium equations in the case of CSM, namely, when high-skill workers are willing to take low-skill jobs and low-skill firms can afford to pay them.

Bellman equations that characterize the employed workers are

$$
\begin{aligned}
r W_{L} & =w_{L}-\delta\left(W_{L}-U_{L}\right) \\
r W_{L(H)} & =w_{L(H)}-\delta\left[W_{L(H)}-U_{H}\right] \\
r W_{H} & =w_{H}-\delta\left(W_{H}-U_{H}\right)
\end{aligned}
$$

where the discounted value of working must be equal to the flow of income (wages) and the expected loss from changing the employment status (losing the job). Corresponding

\footnotetext{
${ }^{8}$ Remember that there are $q$ low-skill workers in the labor force and $\phi$ low-skill jobs offered. Also, fraction $\gamma$ of unemployed is low-skill, and high-skill workers can take both types of jobs and both types of jobs meet workers at the same rate.
} 
equations for unemployed workers are

$$
\begin{aligned}
r U_{L} & =b+\phi m(\theta)\left(W_{L}-U_{L}\right) \\
r U_{H} & =b+m(\theta)\left[\phi W_{L(H)}+(1-\phi) W_{H}-U_{H}\right]
\end{aligned}
$$

where the discounted value of being unemployed must be equal to the flow of income (unemployment benefits) and the expected gain from finding a job. Bellman equations for the active firms are

$$
\begin{aligned}
r J_{L} & =\left(y_{L}-w_{L}-c\right)-\delta\left(J_{L}-V_{L}\right), \\
r J_{L(H)} & =\left[y_{L(H)}-w_{L(H)}-c\right]-\delta\left[J_{L(H)}-V_{L}\right], \\
r J_{H} & =\left(y_{H}-w_{H}-c\right)-\delta\left(J_{H}-V_{H}\right)
\end{aligned}
$$

where the discounted value of the job must be equal to the flow of profits earned by the active firm and the expected loss from changing the labor market status (becoming an inactive firm). Corresponding equations for inactive firms are

$$
\begin{aligned}
& r V_{L}=-c+z(\theta)\left[\gamma J_{L}+(1-\gamma) J_{L(H)}-V_{L}\right] \\
& r V_{H}=-c+z(\theta)(1-\gamma)\left(J_{H}-V_{H}\right)
\end{aligned}
$$

where the discounted value of the vacancy must be equal to the flow of income lost by maintaining the vacancy open and the expected gain from switching to the active status. The condition for CSM equilibrium to exist is that matches between high-skill workers and low-skill jobs are realized, which happens when ${ }^{9}$

$$
y_{L}-c>r U_{H}
$$

There is free entry into the market, yet as the value of the vacancy decreases to zero no more firms enter, i.e. in steady-state equilibrium

$$
V_{L}=0 \text { and } V_{H}=0 .
$$

Definition 1 In Cross Skill Matching (CSM) steady-state equilibrium the following conditions must hold:

(i) workers' Bellman equations (10), (11), (12), (13) and (14),

\footnotetext{
${ }^{9}$ Conditions $J_{L(H)}>V_{L}$ and $W_{L(H)}>U_{H}$ must hold. We can obtain the CSM equilibrium condition by processing the corresponding Bellman equations.
} 
(ii) firms' Bellman equations (15), (17), (18) and (19),

(iii) Nash bargaining conditions (1), (2) and (3),

(iv) steady state conditions (5) and (7),

(v) zero vacancy value conditions (21) and

(vi) CSM equilibrium condition (20).

In CSM steady-state equilibrium the aggregate level of output is

$$
Y^{C S M}=E_{L} y_{L}+\phi E_{H} y_{L}+(1-\phi) E_{H} y_{H}
$$

Each worker employed in low-skill firms produces $y_{L}$, each worker employed in high-skill firms produces $y_{H}$.

Given that we are also interested in measuring social welfare we account for the lifetime utility of both employed and unemployed workers as follows

$$
\Omega^{C S M}=E_{L} W_{L}+\phi E_{H} W_{L(H)}+(1-\phi) E_{H} W_{H}+\left(q-E_{L}\right) U_{L}+\left(1-q-E_{H}\right) U_{H} .
$$

\subsection{Ex Post Segmentation Equilibrium}

Let us describe now the equilibrium equations in the case of EPS, when high-skill workers are only matching with high-skill firms.

Bellman equations that characterize the employed workers are

$$
\begin{aligned}
& r W_{L}=w_{L}-\delta\left(W_{L}-U_{L}\right), \\
& r W_{H}=w_{H}-\delta\left(W_{H}-U_{H}\right)
\end{aligned}
$$

where the discounted value of working must be equal to the flow of income (wages) and the expected loss from changing the employment status (losing the job). Corresponding equations for unemployed workers are

$$
\begin{aligned}
r U_{L} & =b+\phi m(\theta)\left(W_{L}-U_{L}\right), \\
r U_{H} & =b+(1-\phi) m(\theta)\left(W_{H}-U_{H}\right),
\end{aligned}
$$

where the discounted value of being unemployed must be equal to the flow of income (unemployment benefits) and the expected gain from finding a job. ${ }^{10}$ Bellman equations

\footnotetext{
${ }^{10}$ Notice that with respect to the CSM equilibrium equation (25) has changed. It reflects now that high-skill unemployed workers are only going to take high-skill jobs.
} 
for the active firms are

$$
\begin{aligned}
r J_{L} & =\left(y_{L}-w_{L}-c\right)-\delta\left(J_{L}-V_{L}\right), \\
r J_{H} & =\left(y_{H}-w_{H}-c\right)-\delta\left(J_{H}-V_{H}\right)
\end{aligned}
$$

where the discounted value of the job must be equal to the flow of profits earned by an active firm and an expected loss from changing the labor market status (becoming an inactive firm). Corresponding equations for inactive firms are

$$
\begin{aligned}
r V_{L} & =-c+z(\theta)\left[\gamma J_{L}+(1-\gamma) J_{L(H)}-V_{L}\right] \\
r V_{H} & =-c+z(\theta)(1-\gamma)\left(J_{H}-V_{H}\right)
\end{aligned}
$$

where the discounted value of the vacancy must be equal to the flow of income lost by maintaining the vacancy open and the expected gain from switching to the active status. The condition for EPS equilibrium to exist is that high-skill workers are matching only with high-skill jobs

$$
y_{L}-c \leq r U_{H}
$$

Definition 2 In Ex Post Segmentation (EPS) steady-state equilibrium, the following conditions must hold:

(i) workers' Bellman equations (22), (23), (24) and (25),

(ii) firms' Bellman equations (26), (27), (28) and (29),

(iii) Nash bargaining conditions (1) and (3),

(iv) steady state conditions (5) and (7),

(v) zero vacancy value conditions (21) and

(vi) EPS equilibrium condition (30).

In EPS steady-state equilibrium the aggregate level of output is

$$
Y^{E P S}=E_{L} y_{L}+E_{H} y_{H}
$$

and social welfare is given by

$$
\Omega^{E P S}=E_{L} W_{L}+E_{H} W_{H}+\left(q-E_{L}\right) U_{L}+\left(1-q-E_{H}\right) U_{H}
$$

\section{Solving the model}

In the steady-state equilibrium the value of both vacancies goes to zero, as in equation (21). Combining the equilibrium equations we can obtain two free entry condition loci 
$\gamma=f_{V_{L}=0}(\theta)$ and $\gamma=f_{V_{H}=0}(\theta)$. The intersection of the two loci determines the fraction of low-skill unemployment $\gamma$ and the market tightness $\theta$. The two functions may be non-monotonic and multiple equilibria may arise.

In order to solve the model numerically we need to specify the matching function. We assume that $M(u, v)=2 \sqrt{u v}$, which implies

$$
\begin{aligned}
m(\theta) & =2 \sqrt{\theta} \text { and } \\
z(\theta) & =\frac{2}{\sqrt{\theta}} .
\end{aligned}
$$

\subsection{Cross Skill Matching Equilibrium}

Rewriting (15)-(16) we get

$$
\begin{aligned}
J_{L} & =\frac{y_{L}-w_{L}-c}{r+\delta}, \\
J_{L(H)} & =\frac{y_{L}-w_{L(H)}-c}{r+\delta}, \\
J_{H} & =\frac{y_{H}-w_{H}-c}{r+\delta} .
\end{aligned}
$$

Using (13) and (14) in combination with (1)-(3) and (10)-(12) we can write

$$
\begin{aligned}
r U_{L} & =\frac{b(r+\delta)+\beta \phi m(\theta)\left(y_{L}-c\right)}{[r+\delta+\beta \phi m(\theta)]} \\
r U_{H} & =\frac{b(r+\delta)+\beta m(\theta)\left[\phi y_{L(H)}+(1-\phi) y_{H}-c\right]}{[r+\delta+\beta m(\theta)]} .
\end{aligned}
$$

Then when $V_{L}=0$, plugging (31), (32), (34) into (18) we get the $\gamma=f_{V_{L}=0}(\theta)$ for low-skill workers

$$
L \text { locus: } c=z(\theta)(1-\beta)\left\{\gamma \frac{\left(y_{L}-c-b\right)}{[r+\delta+\beta \phi m(\theta)]}+(1-\gamma) \frac{\left(y_{L}-c-b\right)(r+\delta)+\beta m(\theta)(1-\phi)\left(y_{L}-y_{H}\right)}{(r+\delta)[r+\delta+\beta m(\theta)]}\right\}
$$

where $\phi$ is given in (9) and is a function of the endogenous $\gamma$ and $\theta$. When $V_{H}=0$, plugging (33), (35) into (19) we get the $\gamma=f_{V_{H}=0}(\theta)$ for high-skill workers

$$
H \text { locus: } c=z(\theta)(1-\beta)(1-\gamma) \frac{\left(y_{H}-c-b\right)(r+\delta)+\beta m(\theta) \phi\left(y_{H}-y_{L}\right)}{(r+\delta)[r+\delta+\beta m(\theta)]} .
$$

Taking the assumed matching function, the locus for low-skill workers can be solved numerically. The locus for high-skill workers can be solved analytically. It is a second 
degree polynomial in $\sqrt{\theta}$

$\begin{aligned} H \text { locus: } \quad & 0=-c(r+\delta) 2 \beta \theta+\left\{-c(r+\delta)^{2}+\frac{4(1-\gamma)^{2}(1-\beta) \beta q\left(y_{H}-y_{L}\right)}{\gamma(1-q)}\right\} \sqrt{\theta} \\ & +2(1-\gamma)(1-\beta)\left\{\left(y_{H}-c-b\right)(r+\delta)+\frac{\beta \delta(q-\gamma)\left(y_{H}-y_{L}\right)}{\gamma(1-q)}\right\} .\end{aligned}$

\subsection{Ex Post Segmentation Equilibrium}

Rewriting (26)-(27) we get (31) and (33). Using (13) and (14) in combination with (1)-(3) and (22)-(23) we get (34) and

$$
r U_{H}=\frac{b(r+\delta)+\beta(1-\phi) m(\theta)\left(y_{H}-c\right)}{[r+\delta+\beta(1-\phi) m(\theta)]} .
$$

Then when $V_{L}=0$, plugging (31), (34) into (28) we get the $\gamma=f_{V_{L}=0}(\theta)$ for low-skill workers

$$
L \text { locus: } c=z(\theta)(1-\beta) \gamma \frac{\left(y_{L}-c-b\right)}{[r+\delta+\beta \phi m(\theta)]} .
$$

When $V_{H}=0$, plugging (33), (36) into (29) we get the $\gamma=f_{V_{H}=0}(\theta)$ for high-skill workers

$$
H \text { locus: } c=z(\theta)(1-\beta)(1-\gamma) \frac{\left(y_{H}-c-b\right)}{[r+\delta+\beta(1-\phi) m(\theta)]} .
$$

Taking the assumed matching function, the locus for low-skill workers is the following polynomial

$L$ locus: $0=\theta \frac{2 c \beta q(1-\gamma)}{(\gamma+q-2 \gamma q)}+\sqrt{\theta} c\left[r+\delta+\frac{\beta \delta(q-\gamma)}{(\gamma+q-2 \gamma q)}\right]-2 \gamma(1-\beta)\left(y_{L}-c-b\right)$ and the locus for high-skill workers $H$ locus: $0=\theta \frac{2 c \beta \gamma(1-q)}{(\gamma+q-2 \gamma q)}+\sqrt{\theta} c\left[r+\delta+\frac{\beta \delta(q-\gamma)}{(\gamma+q-2 \gamma q)}\right]-2(1-\gamma)(1-\beta)\left(y_{H}-c-b\right)$.

Once the values of $\gamma$ and $\theta$ are obtained, all equilibrium values are easily obtained using the equilibrium equations.

\section{Parametrization and comparative statics}

In this section we calibrate our model and then carry out a comparative statics exercise to account for different policy measures that can possibly compensate for the welfare effects of offshoring. By changing the model's parameters it is possible to examine three 
possible scenarios: (i) the movement from a CSM equilibrium to another CSM; (ii) a switch from a CSM equilibrium to an EPS equilibrium; and (iii) the movement from an EPS equilibrium to another EPS.

In the offshoring literature offshoring is often identified as a source of skill-biased technical change. In our setting, skill-biased technical change can be seen as an increase of output produced in high-skill jobs while the output from low-skill jobs remains constant. Similarly, this can also be represented as a fall in the productivity levels of low-skill workers while keeping the productivity of high-skill workers fixed. Hence, introducing cheap imports due to a liberalization process or the increase of offshoring will reduce the value of the output of low-skill jobs. ${ }^{11}$ We will focus on the latter case alone as is the one consistent with offshoring.

The parametrization of the model will differ when dealing with steady state changes from a CSM to another CSM equilibrium, and when analyzing the switch from CSM to EPS, or from an EPS to another EPS. Notice that the EPS equilibrium is more likely to exist when the productivity gap between the two types of workers is high, i.e. when $y_{H}>>y_{L}$, and consequently the wages in low-skill firms are too low to entice high-skill workers into these jobs.

We use the following baseline parameters: the rate at which the employment relationship is broken is $\delta=0.2$, meaning that jobs last on average 5 years, agents discount the future at a constant rate $r=0.05$, there are $q=2 / 3$ of low-skill workers in the labor force (and 1/3 who are high-skill), and the bargaining power of workers is the same as that of the firms, $\beta=0.5$. The baseline value of the unemployment benefit is $b=0.1$ and the cost of opening a vacancy is $c=0.3$. The output produced by high-skill workers in a high-skill firm is assumed to be $y_{H}=1.2$. The baseline value of the output in a low-skill firm will change in order to generate a CSM or an EPS equilibrium. When, under the baseline parameters, the productivity gap is such that $y_{H}-y_{L} \leq 0.327$, then the CSM equilibrium exists, i.e. high-skill workers match with both high and low-skill firms. However, high-skill workers may stop matching with low-skill firms when the productivity gap is such that $y_{H}-y_{L}>0.25$. Thus, we have an interval where both equilibria are possible and the actual outcome depends on the expectations of high-skill workers about the economy and their willingness to accept, or not, a low-skill job.

Let us now preview the general initial effects of offshoring in our model - that is, previous to any compensating policy measure. As seen in Table 1, a reduction in the productivity of low-skill labor yields the following qualitative results: (a) it raises the unemployment rate $(u)$; (b) it reduces the fraction of vacancies that are low-skill $(\phi)$; (c) it brings down the wages in low-skill jobs $\left(w_{L}\right.$ and $\left.w_{L(H)}\right)$; (d) it cuts production

\footnotetext{
${ }^{11}$ Remember that offshoring intensity can be measured as an intermediate inputs ratio or a vertical specialization index as we did above.
} 
down $(Y)$; and (e) it reduces welfare $(\Omega)$. Changes in the wages of the high-skill workers depend on the kind of equilibrium: high-skill wages are harmed under CSM but improved under EPS.

We now proceed to analyze two comparative statics exercises, involving two appreciably different policy measures with quite different outcomes - an increase of the unemployment benefits and a reduction of the vacancy costs. 


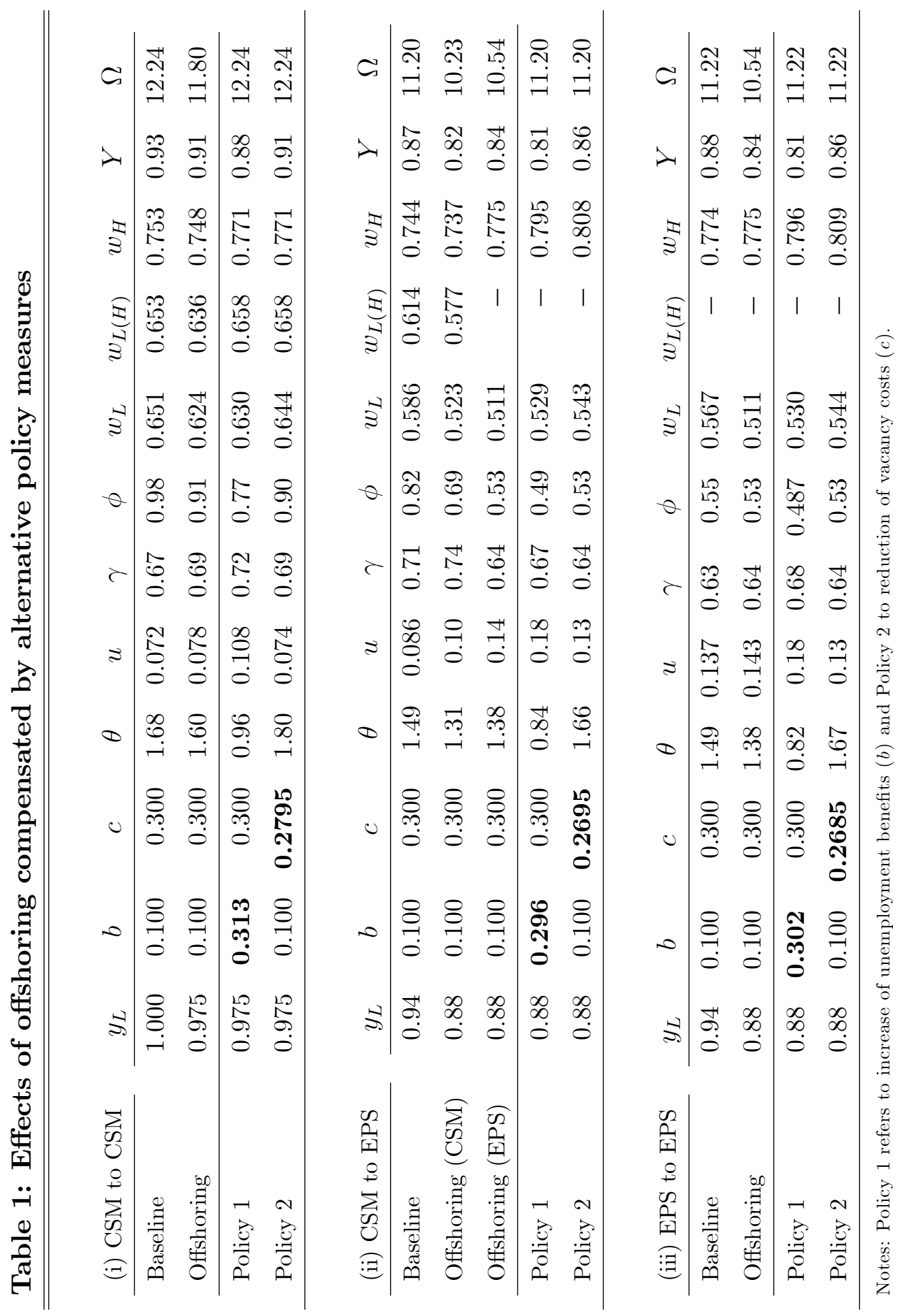




\subsection{Unemployment benefits}

Let us first consider the effects of increasing the unemployment benefits $(b)$ right after offshoring sets in, as displayed in the rows labeled 'Policy 1' in Table 1. We can see there, in segment (i), that a drop in $y_{L}$ from 1 to 0.975 (or a widening of the productivity gap from 0.2 to 0.225 ) can be fully compensated in terms of welfare (last column to the right) by increasing the unemployment benefits from 0.1 to 0.313 (213\%). As a result, the wages of offshored workers $w_{L}$ drop, but less than in the case of no compensation. Furthermore, the wages of high-skill workers in both types of jobs increase - as the reservation wage increases, firms have to compensate with higher wages to attract workers. As more workers are now idle, output falls even further, from 0.93 to 0.91 when no compensation and to 0.88 when compensated. Moreover, the unemployment rate rises from $7.2 \%$ to $7.8 \%$ when no compensation and to $10.8 \%$ when compensated.

If the initial position is such that the productivity gap is wider, as in segment (ii), and income $y_{L}$ further decreases, we may observe a switch in the equilibrium. In this case we reduce $y_{L}$ from 0.94 to 0.88 (a $6.38 \%$ drop in low-skill output) and the output gap goes from 0.26 to $0.32(23 \%)$. Welfare compensation in the form of increased unemployment benefits pushes the economy into an EPS equilibrium. A compensating change in the unemployment benefits requires $b$ to rise a sizeable $196 \%$. We can see, however, the sharp rise of the unemployment rate along with the significant fall of the wages of low-skill workers, yet the ones under EPS equilibrium with intervention are comparable to the ones under CSM equilibrium without intervention. High-skill workers would benefit again as their wages $w_{H}$ experience an $8 \%$ increase.

Segment (iii) describes the passage from an EPS to another EPS equilibrium and is not that different from the previous one - in fact, the 'Offshoring' rows in both segments are identical, yet not the 'Baseline' rows as the equilibria we depart from are different. Notice that, as before, it would require a huge rise of the unemployment benefits $(202 \%)$ to maintain previous levels of welfare.

Consequently, we can argue that raising the unemployment benefits to compensate for the welfare loss that is bound to happen when low-skill offshoring takes place is a rather expensive and therefore unjustified counter measure - as the improvement in welfare comes largely from paying idle workers.

Figure 4 puts some color to our previous exercise and shows how active governments have been for the past 15 years in relation to labor market policies in general. With a few exceptions, we observe an extensive declining trend in active and passive policy measures, which, in many cases, is quite remarkable. ${ }^{12}$ For example, Spain, Portugal, Austria, Czech Republic and the US have experienced mild to very little increases of their spending in both active and passive measures, while for the rest the trend has been

\footnotetext{
${ }^{12}$ The sample here is the same as in the introduction.
} 
the opposite. It is also to remark the very sharp reduction which has taken place in the Baltic countries, quite likely as a result of the lack of long-run sustainability of their extensive welfare states. Notice that, according to our welfare analysis, policy makers in any of these countries would have to push for a trebling of their current expenditures in labor market policies. This is politically impossible and at the same time highly disruptive, even for countries with 'light welfare states' and no debt problems. Not only will this pose a future threat for public finance, but it will also represent a major disincentive for those willing to work.

Figure 4: Labor market policies, \% of GDP

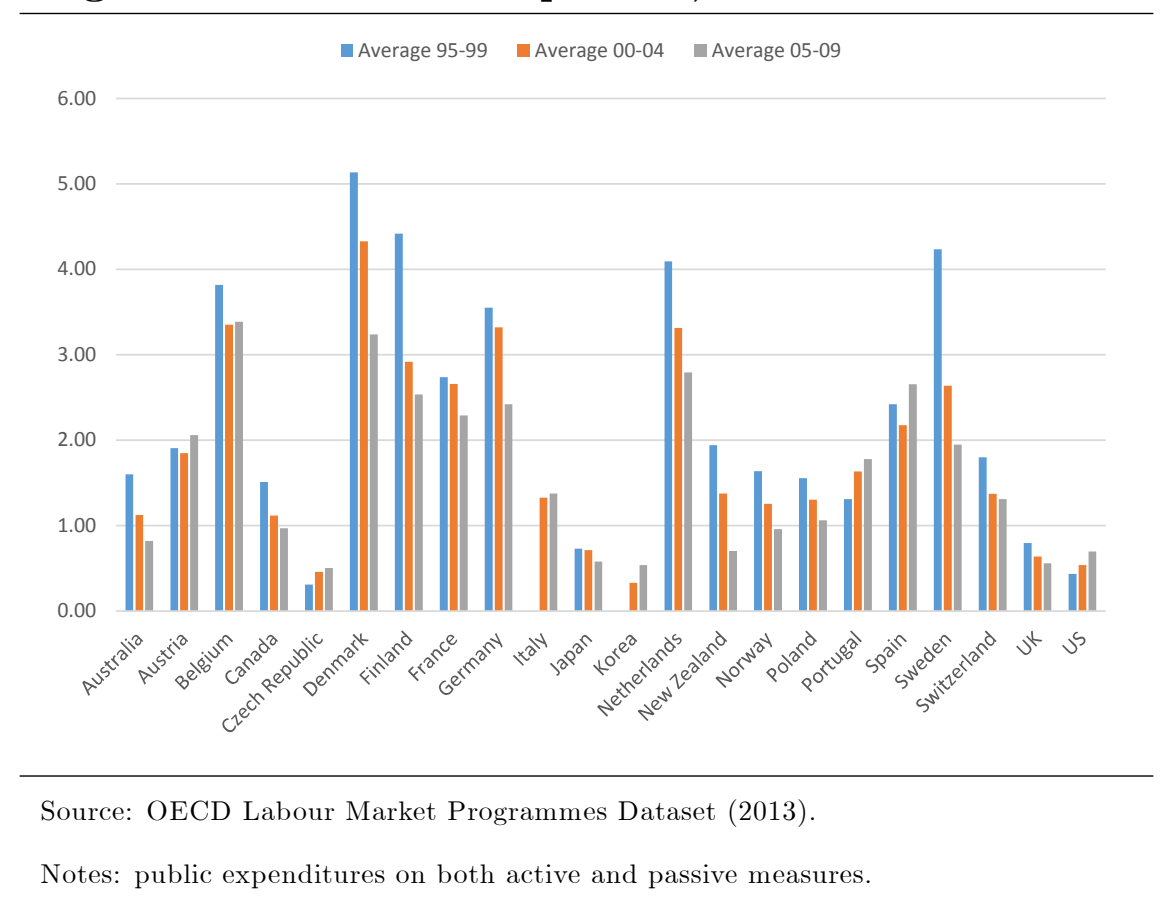

\subsection{Labor market flexibility}

Let us now discuss the effects of our alternative policy measure, the flexibilization of the labor market by way of a reduction of the vacancy costs $(c)$, as seen in the rows labeled 'Policy 2' in Table 1. A fall of $y_{L}$ in segment (i) from 1 to 0.975 (2.5\%) due to offshoring can now be offset by a cutback of the vacancy costs by the order of $6.8 \%$, from 0.3 to 0.2795 . As in the case of unemployment benefits the wages of low-skill workers threatened by offshoring go down, albeit not as much as before, whereas the wages of high-skill workers in both jobs increase exactly as much as with the previous measure. Output, even when lower than in the baseline scenario, is not as much reduced as with Policy 1, and the unemployment rate stays at a reasonable $7.4 \%$ which is very similar to the original $7.2 \%$ - the unemployment rate would have stayed at $7.8 \%$ when no measure or much higher at $10.8 \%$ under the alternative policy. 
Accounting for a wider productivity gap and the possibility of a switch in the equilibrium in segment (ii), we notice that the needed reduction in the vacancy cost would have to be now of the order of $10.2 \%$. The unemployment rate, in turn, even when higher than the baseline case, is slightly lower than without flexibilization, while the same can be said about the wages for low-skill-lower than the baseline case but significantly higher than when no flexibilization, both under CSM or EPS. High-skill workers experience now a rise of around $10 \%$ in $w_{H}$, with respect to the scenario right after offshoring takes place under a CSM equilibrium. Finally, segment (iii) shows that the reduction in the vacancy cost necessary to compensate for offshoring should now be of around $10.5 \%$.

Notice further the stark differences in performance as delivered by the two policies, which can be clearly seen in rows 'Policy 1' and 'Policy 2'. In spite of showing the same level of welfare, as that was the goal of the exercise, we can point out that the second policy consistently displays a significantly lower unemployment rate, higher wages for low and high-skill workers (but particularly for the former), and a higher level of output. Overall, Policy 2 seems to be more desirable on account of its sustainability, given that it only represents a reduction of the vacancy costs ranging from around $7 \%$ to $10 \%$ - no doubt something achievable and within the reach of most policy makers.

Figure 5 shows the changes in the level of employment protection for the same group of countries as in the previous sections. We can see that, in spite of the differences among countries, the policy regarding employment protection has remained very much the same. Notice that even when $c$ in our model simply refers to the cost of creating and maintaining a vacancy, it is still accounted for in the OECD strictness indicator as this includes both the regulations on dismissals and the use of temporary contractsthe latter having a direct impact on the hiring process of firms. Vacancy costs usually include advertisement, the time cost of the internal recruiter, the time cost taken by the interviews, drugs screens and background checks, and various pre-employment assessment tests. When it comes to the indicator presented here, a reduction of the vacancy cost may be brought about by a loosening up of the regulations involving temporary workers, as this will probably reduce the administrative burden faced by the firms.

Likewise, employment subsidies seem bound to have the same effect on hiring (Phelps, 1994) either at the expense of the taxpayer or lower welfare entitlements. Finally, it can be argued too that reducing the firing costs can bring $c$ down, as this can be broadly thought as including the costs which firms will have to face sooner or later. Labor market policies can strongly define the pattern of trade and the effects of trade in general (see Helpman and Itskhoki, 2007), and offshoring is just another form of trade. ${ }^{13}$

\footnotetext{
${ }^{13}$ Davidson and Matusz (2006) evaluate the effects of four different policies in the broader context
} 
Figure 5: Employment protection, strictness indicator

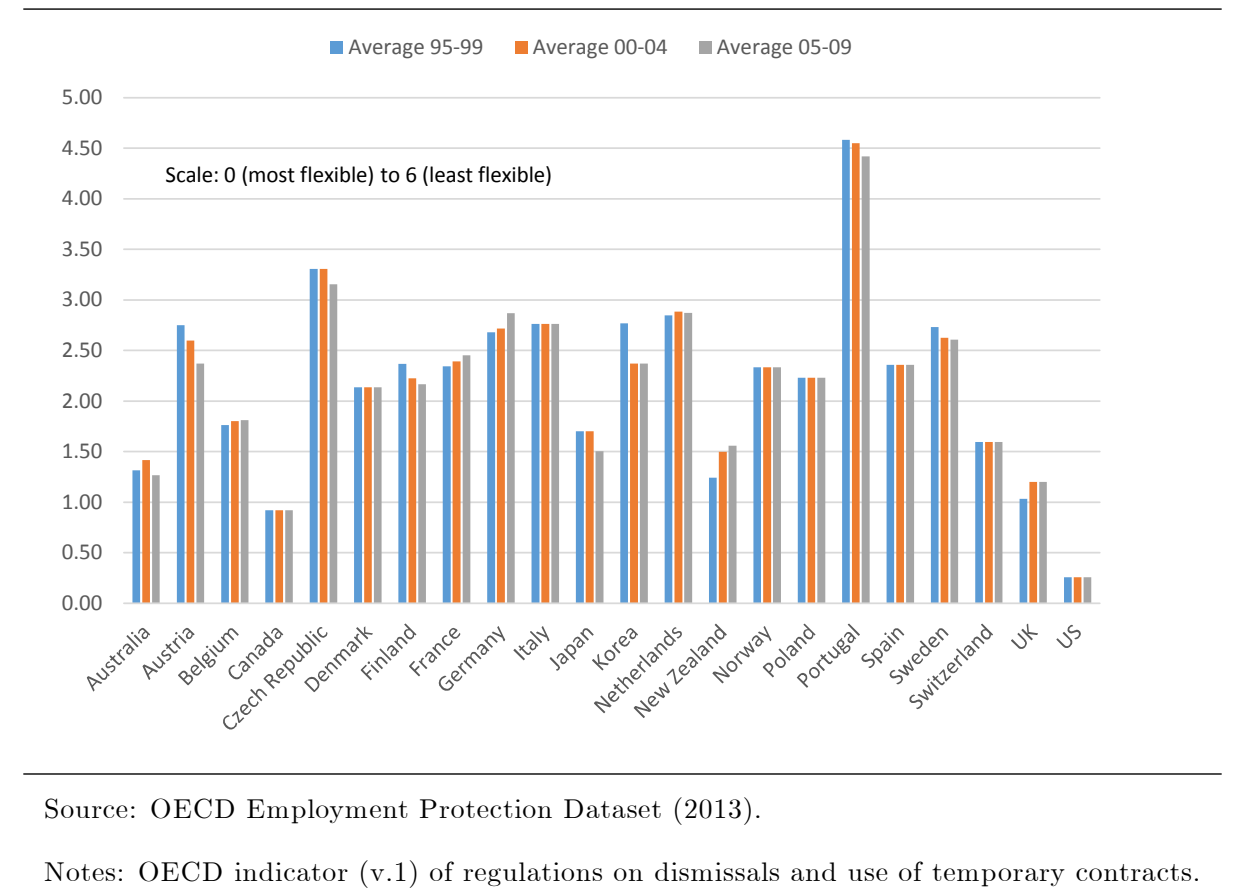

\section{Conclusions}

We have relied on the model by Albrech and Vroman (2002) to perform a quantitative analysis of the effects of low-skill offshoring on the welfare of the economy. Two government policies, unemployment insurance and labor market flexibilization, were used to offset the negative effects of offshoring. We show that the welfare loss due to low-skill offshoring can be compensated with both measures. As per our welfare analysis, it would require a huge increase in the unemployment benefits to compensate for the negative welfare effects of offshoring. On the other hand, it would only require a relatively small reduction in the vacancy cost to achieve the pre-offshoring welfare level. Thus, the recommended welfare improving tool is flexibilization. It is clearly more employable due to its lower costs and its being less intrusive in terms of work disincentives and economic activity.

Possible extensions of the model include, for example, adding the government budget and accounting for the skill upgrading of low-skill workers. We think these additions will help assessing, on the one hand, the effect of the chosen policies on public finance, and on the other, the effect of recycling and re-training programs on the future productivity levels of low-skill workers. Calibration of the model for some of the countries shown in Figures 4 and 5 is also in the agenda.

of globalization: unemployment benefits, training subsidies, employment or wage subsidies. They conclude that wage subsidies are the preferred policy as they give the highest incentive for re-employment. 


\section{References}

[1] Albrecht, James and Vroman, Susan, 2002. A Matching Model with Endogenous Skill Requirements, International Economic Review 43, 283-305.

[2] Bhagwati, Jagdish, Panagariya, Arvind, and Srinivasan, T.N., 2004. The Muddles over Outsourcing, Journal of Economic Perspectives 18, 93-114.

[3] Davidson, Carl, and Matusz, J. Steven, 2006. Trade Liberalization and Compensation, International Economic Review 47 , 723-747.

[4] Davidson, Carl, Matusz, J. Steven, and Shevchenko, Andrei, 2008. Outsourcing Peter to pay Paul: High-skill Expectations and Low-skill Wages with Imperfect Labor Markets, Macroeconomic Dynamics 12, 463-479.

[5] Diamond, Peter A., 1982. Aggregate Demand Management in Search Equilibrium, Journal of Political Economy 90, 881-894.

[6] Feenstra, Robert C. and Hanson, Gordon H., 1996. Globalization, Outsourcing, and Wage Inequality, The American Economic Review 86, 240-245.

[7] Helpman, Elhanan and Itskhoki, Oleg, 2007. Labor Market Rigidities, Trade and Unemployment, NBER Working Paper No. 13365.

[8] Jung, Jaewon and Mercenier, Jean, 2014. On Modeling Task, Skill and Technology Upgrading Effects of Globalization with Heterogeneous Labor, Economic Modelling 39, 49-62.

[9] Mitra, Devashish and Ranjan, Priya, 2013. Fairness, Search Frictions, and Offshoring, The B.E. Journal of Economic Analysis \& Policy 13, 137-172.

[10] Mortensen, Dale T., 1982. Property Rights in Mating, Racing, and Related Games, American Economic Review 72, 968-979.

[11] Pissarides, Christopher A., 2000. Equilibrium Unemployment Theory, 2nd edition Cambridge, MA: MIT Press

[12] Phelps, Edmund S., 1994. Low-Wage Employment Subsidies versus the Welfare State, American Economic Review, AEA Papers and Proceedings 84, 54-58.

[13] Ranjan, Priya, 2013a. Offshoring, Unemployment, and Wages: The Role of Labor Market Institutions, Journal of International Economics 89, 172-186.

[14] Ranjan, Priya, 2013b. Offshoring, Unemployment, and Welfare with Risk Averse Workers, Working Paper, The Selected Works of Priya Ranjan. 
[15] Rogerson, Richard, Shimer, Robert and Wright, Randall, 2005. Search-Theoretic Models of the Labor Market: A Survey, Journal of Economic Literature 43, 959988.

[16] Samuelson, Paul A., 2004. Where Ricardo and Mill Rebut and Confirm Arguments of Mainstream Economists Supporting Globalization, Journal of Economic Perspectives 18, 135-146. 